\title{
Moulding of carbon fiber reinforced polycarbonate (CF/PC) using UD tape
}

\author{
M. Shinohara ${ }^{1}$, S. Isshiki ${ }^{2}$, Y. Fukushima ${ }^{2}$, T. Katayama ${ }^{2}$ \\ \& K. Tanaka ${ }^{2}$ \\ ${ }^{I}$ Department of Mechanical Engineering, \\ Maizuru National College of Technology, Japan \\ ${ }^{2}$ Department of Biomedical Engineering, Doshisha University, Japan
}

\begin{abstract}
Carbon Fiber Reinforced Plastics (CFRP) are attracting attention in the automotive industry for their light-weighted properties. The thermoset plastics like epoxies are mainly used as a matrix of CFRP in such an industry. The curing time of the thermosetting resin is timely leading to poor productivity. Within thermoplastic resins, polycarbonate (PC) is excellent for its impact properties; thus it is expected to be used for matrices of composite materials for automotive. Moreover, in order to obtain outstanding strength, the application of continuous fiber is anticipated for reinforcing fiber. However, large-scale equipment is needed and the effort of press load is required in order to impregnate PC into continuous fiber. Recently UD tape of $\mathrm{CF} / \mathrm{PC}$ in which $\mathrm{PC}$ matrix has been impregnated to a $\mathrm{CF}$ bundle has been developed. In this study, carbon fiber reinforced polycarbonate $(\mathrm{CF} / \mathrm{PC})$ was moulded by using UD tape and the practicality of UD tape was examined by studying the mechanical property aiming at shortening the moulding time.

Keywords: carbon fiber polycarbonate (PC), CFRTP, UD tape, plain weave, non crimp fabric.
\end{abstract}

\section{Introduction}

Carbon Fiber Reinforced Plastics (CFRP) have advantages in high-specific strength and high-specific modulus, hence the demand of CFRP is increasing in the aerospace, automotive and sports industries etc [1-8]. Especially the thermoset plastics like epoxis are mainly used as a matrix of CFRP in the 
automotive industry. The FRP using thermosetting resin has bad productivity, and it cannot be melted or reformed after moulding, making recycling difficult. On the other hand, Carbon Fiber Reinforced Thermoplastics (CFRTP) is recyclable, good in productivity and impact strength; thus it is expected to be widely applied within the industry. Therefore it is appropriate to use CFRTP when CFRP is used for automotive applications [9]. Meanwhile it is necessary to choose an excellent matrix in strength, impact resistance, and heat resistance when using CFRTP for automotive materials. Moreover, in order to obtain outstanding strength, the application of continuous fiber is expected for reinforcing fibers.

Polycarbonate (PC) has a high impact strength compared to other plastics, thus it is expected to be used as the matrix of CFRTP. However, large-scale equipment is needed and higher press load is required in order to impregnate PC into continuous fiber [10]. Recently UD tape of CF/PC in which PC matrix has been impregnated to a CF bundle has been developed. In this study, carbon fiber reinforced polycarbonate (CF/PC) was moulded using two kinds of semi product, plain weave and sheet stacking, that were made with UD tape, and their mechanical properties were evaluated.

\section{Materials and experimental procedure}

\subsection{Materials}

UD tape (Teijin Chemicals Ltd., Japan) impregnated CF with PC was used. The width of UD tape is $7.5 \mathrm{~mm}$ and Vf is $40 \%$. Two kinds of specimens were prepared using UD tape. One was moulded by processing UD tape into a plain weave. Hereafter, this $\mathrm{CF} / \mathrm{PC}$ moulding is called $\mathrm{CF} / \mathrm{PC}$ (plain weave: UD). For the other one, UD tape was arranged unidirectionally, and it was fabricated one layer at a time in the shape of a sheet, and moulded by laminating at $0^{\circ} / 90^{\circ}$. This $\mathrm{CF} / \mathrm{PC}$ specimen is called $\mathrm{CF} / \mathrm{PC}$ (sheet: UD). The specimen using non-crimp fabric (NCF) was also prepared for comparison. The non-crimp stitched carbon fabric (NCF, $\left.300 \mathrm{~g} / \mathrm{m}^{2},\left[0^{\circ} / 90^{\circ}\right]\right)$, using PAN-based carbon fibers, being stitched together by Polyester sewing thread, were used as the reinforcing fiber and PC films (PC-2151, Teijin Chemicals Ltd., Japan) was used for the matrix. This $\mathrm{CF} / \mathrm{PC}$ specimen is called $\mathrm{CF} / \mathrm{PC}(\mathrm{NCF})$.

\subsection{Moulding process}

For moulding specimens using NCF, the optimal condition in past research was adapted [11]. Specimens were moulded by high-speed compression moulding process (to be referred as IH system) using an electromagnetic induction system [11]. Kapton ${ }^{\circledR}$ film (200H, Du Pont-Toray Co., Ltd., Japan) was used as a vacuum bag. After putting the material inside the vacuum bag, inside pressure is reduced to under $1 \mathrm{kPa}$ before and during moulding by a vacuum pump. All moulding conditions are shown in Table 1. Cross sections of the specimens were observed by scanning electron microscope (SEM, SEM-6390LT, JEOL Ltd., Japan) for evaluating resin impregnation. 
Table 1: $\quad$ Moulding conditions of $\mathrm{CF} / \mathrm{PC}$.

\begin{tabular}{|c|c|c|c|c|c|}
\hline Specimens & $\begin{array}{c}\text { Maximum } \\
\text { Temperature } \\
{\left[{ }^{\circ} \mathrm{C}\right]}\end{array}$ & $\begin{array}{c}\text { Pressure } \\
{[\mathrm{MPa}]}\end{array}$ & $\begin{array}{l}\text { Holding time at } \\
\text { maximum } \\
\text { temperature }[\mathrm{s}]\end{array}$ & Vacuum & $\operatorname{Vf}[\%]$ \\
\hline $\begin{array}{c}\mathrm{CF} / \mathrm{PC} \\
\text { (plain } \\
\text { weave: } \\
\text { UD) }\end{array}$ & 300 & \multirow{3}{*}{6} & 90 & \multirow[t]{2}{*}{$\begin{array}{l}\text { Without } \\
\text { vacuum }\end{array}$} & \multirow{3}{*}{40} \\
\hline $\begin{array}{c}\mathrm{CF} / \mathrm{PC} \\
\text { (sheet: UD) }\end{array}$ & 280 & & 30 & & \\
\hline $\begin{array}{l}\mathrm{CF} / \mathrm{PC} \\
(\mathrm{NCF})\end{array}$ & 300 & & 150 & $\begin{array}{l}\text { Vacuum } \\
\text { assisted }\end{array}$ & \\
\hline
\end{tabular}

\subsection{Evaluation of mechanical properties}

Three points bending tests were conducted by universal material testing machine (5566, Instron, USA), following the recommended testing procedures as described in JIS-K7074. The dimension of specimens was set at $100 \times 15 \times 2 \mathrm{~mm}^{3}$. The specimen support span was $80 \mathrm{~mm}$. The cross-head displacement rate was set for $5 \mathrm{~mm} / \mathrm{min}$.

The drop weight impact tests were conducted using the instrumented drop weight impact test machine (IITM-18, Yonekura Co., Japan). The specimen configuration was at a regular octagonal shape of $25 \mathrm{~mm}$ in side length. The specimen was fixed using a suppression board with a hole of $40 \mathrm{~mm}$ in diameter; and a hemisphere of $10 \mathrm{~mm}$ in diameter was used as the striker. Mass of drop weight was $2.0 \mathrm{~kg}$. In order to apply a $7 \mathrm{~J}$ per $1 \mathrm{~mm}$ in specimen thickness, the height of drop weight was adjusted.

\section{Result and discussion}

\subsection{Evaluation of impregnation}

Fig. 1 shows the cross section of moulded CF/PC (plain weave: UD). Some voids were observed in fig.1. Some cavities due to weaving for CF/PC (plain weave: UD) could be a one reason for these voids. Fig. 2 shows the cross section of moulded CF/PC (sheet: UD). Number of voids for the CF/PC (sheet: UD) is far lowered than that for $\mathrm{CF} / \mathrm{PC}$ (plain weave: UD). Fig.3 shows the cross section of moulded $\mathrm{CF} / \mathrm{PC}(\mathrm{NCF})$. Impregnation of $\mathrm{CF} / \mathrm{PC}(\mathrm{NCF})$ is worse than $\mathrm{CF} / \mathrm{PC}$ (sheet: UD). Due to the high viscosity of polycarbonate resin, direct moulding using PC films it is difficult to mould CF/PC with good impregnation. 


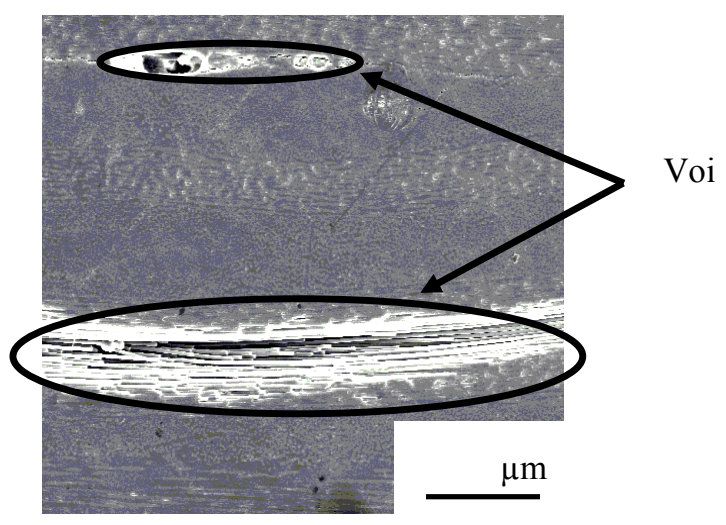

Figure 1: $\quad$ SEM observation of plain $\mathrm{CF} / \mathrm{PC}$ (plain weave: UD) cross section.

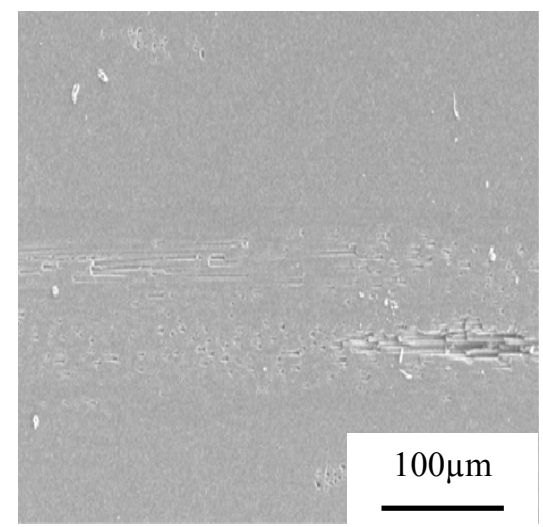

Figure 2: $\quad$ SEM observation of $\mathrm{CF} / \mathrm{PC}$ (sheet: UD) cross section.

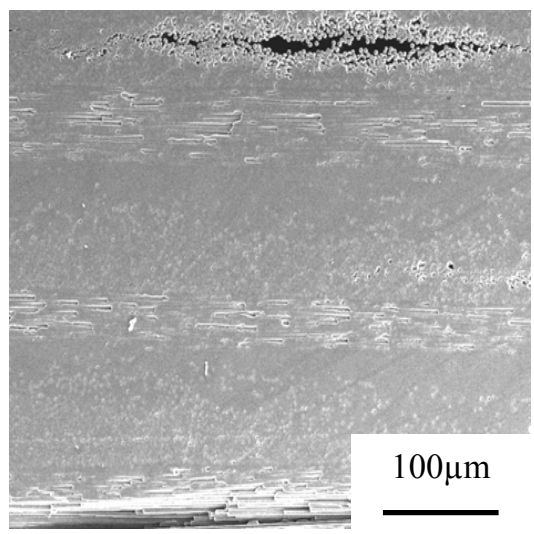

Figure 3: $\quad$ SEM observation of $\mathrm{CF} / \mathrm{PC}(\mathrm{NCF})$ cross section. 


\subsection{Results of three point bending test}

The result of three-point bending testing of the CF/PC (plain weave: UD), CF/PC (sheet: UD) and $\mathrm{CF} / \mathrm{PC}$ (NCF) are shown in figs.4 and 5. According to figs. 4 and 5 it turns out that there is remarkable difference between $\mathrm{CF} / \mathrm{PC}$ (plain weave: UD) and CF/PC (sheet: UD). Fig.6 shows the CF/PC (plain weave: UD) specimen of bending test. Large standard deviation for the results of $\mathrm{CF} / \mathrm{PC}$ (plain weave: UD) shown in fig. 5 is due to the difference in the fractured position of the outermost layer of the specimen. When the fractured position was in between UD tapes, specimens fracture at low stress. On the other hand, when the fractured position was in the UD tape, the bending strength was high. According to figs. 4 and 5 bending strength of the CF/PC (sheet: UD) is high and has little standard deviation. Fig.7 shows the CF/PC (sheet: UD) specimen of bending test. In addition, $\mathrm{CF} / \mathrm{PC}$ (sheet: UD) have fractured in the centre of specimen mostly unlike a $\mathrm{CF} / \mathrm{PC}$ (plain weave: UD). The results of flexural modulus in $\mathrm{CF} / \mathrm{PC}$ (plain weave: $\mathrm{UD}$ ), $\mathrm{CF} / \mathrm{PC}$ (sheet: UD) and $\mathrm{CF} / \mathrm{PC}(\mathrm{NCF})$ are shown in fig.8. Flexural modulus in $\mathrm{CF} / \mathrm{PC}$ (plain weave: UD) is lower than

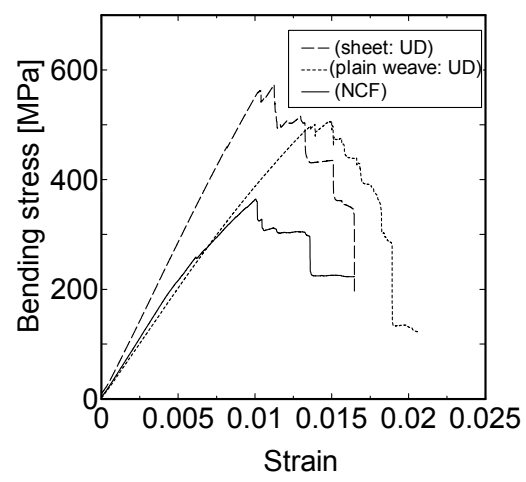

Figure 4: $\quad$ Stress-strain curve of three point bending test.

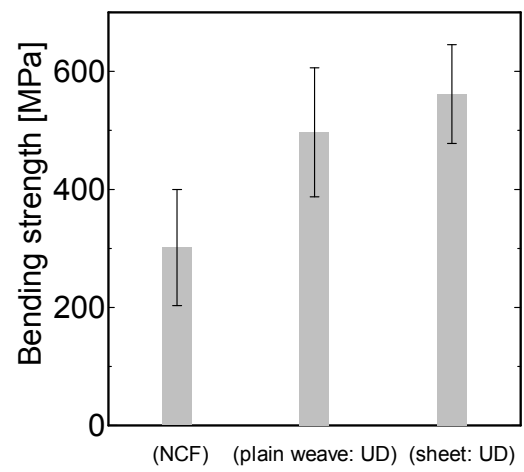

Figure 5: Bending strength. 


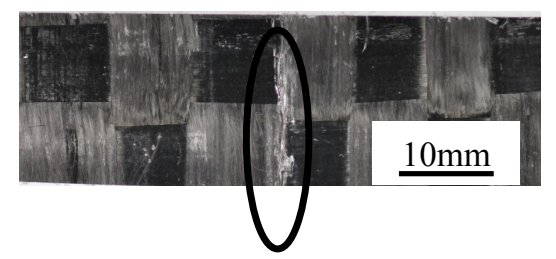

(a) The fractured position was in between UD tapes.

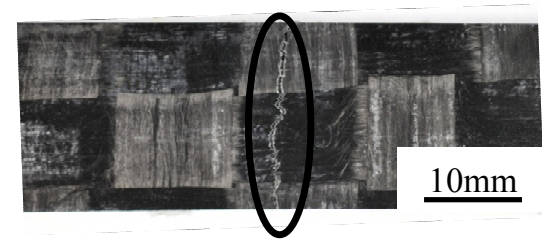

(b) The fractured position was in the UD tape.

Figure 6: $\quad \mathrm{CF} / \mathrm{PC}$ (plain weave: UD) specimen of bending test.

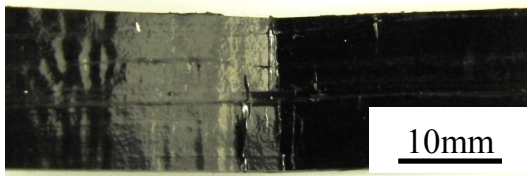

Figure 7: $\quad \mathrm{CF} / \mathrm{PC}$ (sheet: UD) specimen of bending test.

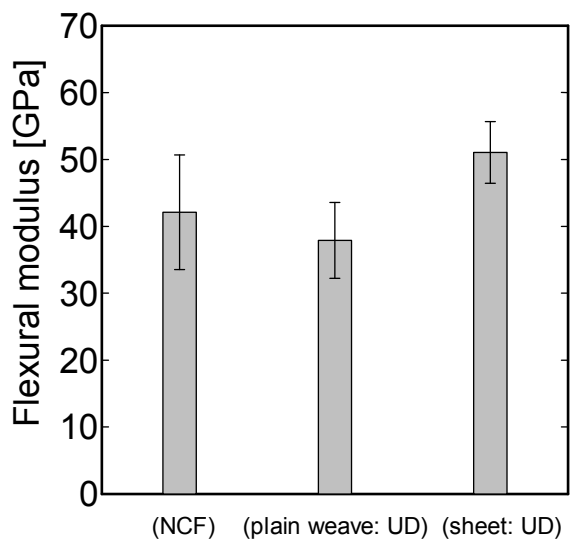

Figure 8: $\quad$ Flexural modulus. 
$\mathrm{CF} / \mathrm{PC}$ (NCF). It is because this flexural modulus is governed by fiber orientation. Moreover, the larger standard deviation in bending strength of $\mathrm{CF} / \mathrm{PC}$ (NCF) come from is the bad impregnation of polycarbonate resin to carbon fiber. Due to the bad impregnation some specimen of $\mathrm{CF} / \mathrm{PC}(\mathrm{NCF})$ resulted in the delamination fracture. $\mathrm{CF} / \mathrm{PC}$ (sheet: UD) has the better bending strength and little standard deviation. Impregnation of $\mathrm{CF} / \mathrm{PC}$ (sheet: UD) appears good compared to other specimens.

\subsection{Results of drop weight impact test}

Fig.9 shows a load-displacement diagram of $\mathrm{CF} / \mathrm{PC}$ (plain weave: UD), $\mathrm{CF} / \mathrm{PC}$ (sheet: UD) and CF/PC (NCF). Fig.10 shows a maximum load of each specimen. Fig. 11 shows an absorbed energy-displacement diagram of $\mathrm{CF} / \mathrm{PC}$ (plain weave: UD), CF/PC (sheet: UD) and CF/PC (NCF). Fig.12 shows an absorbed energy of each specimen. According to figs.10 and 11, CF/PC (plain weave: UD) and $\mathrm{CF} / \mathrm{PC}$ (sheet: UD) are higher than $\mathrm{CF} / \mathrm{PC}(\mathrm{NCF})$ in maximum load and

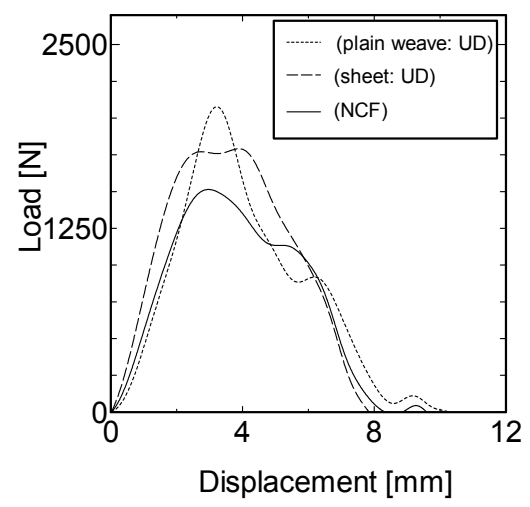

Figure 9: Load-displacement curve of drop weight impact test.

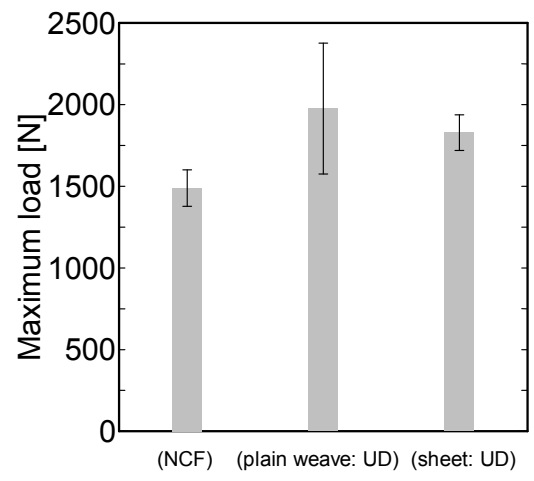

Figure 10: Maximum load of drop weight impact test. 


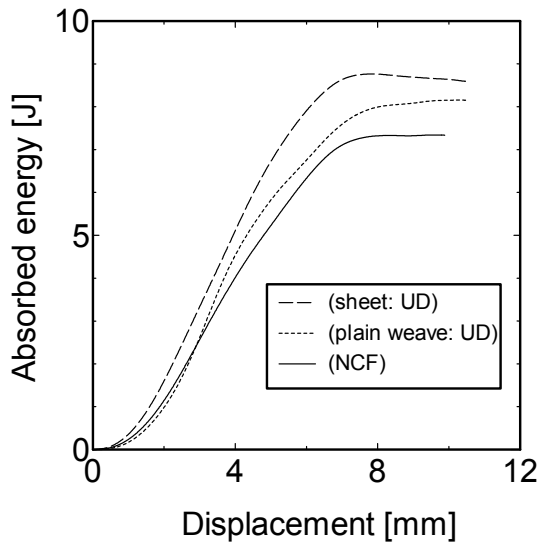

Figure 11: Absorbed energy-displacement curve of drop weight impact test.

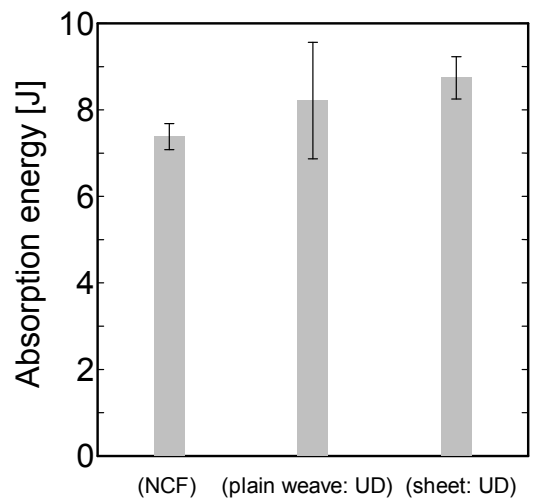

Figure 12: Absorbed energy of drop weight impact test.

absorbed energy. Moreover, characteristic of CF/PC (plain weave: UD) and $\mathrm{CF} / \mathrm{PC}$ (sheet: UD) is so different, although they used the same UD tapes. Maximum load of CF/PC (plain weave: UD) is higher than CF/PC (sheet: UD). $\mathrm{CF} / \mathrm{PC}$ (sheet: UD) has constant load just after the maximum load. Same as the three point bending test result, statistical variability in the CF/PC (plain weave: $\mathrm{UD})$ is due to the difference in the fractured position part of the outermost layer of the specimen. When the fractured position was in between UD tapes, specimens fractured at low maximum load and absorbed energy. On the other hand, when the fractured position was in the UD tape, the bending strength was high. 


\section{Conclusion}

In this study, carbon fiber reinforced polycarbonate $(\mathrm{CF} / \mathrm{PC})$ was moulded using two kinds of semi product, plain weave and sheet stacking, that were made with UD tape, and their mechanical properties were evaluated. The investigation yielded the following conclusions:

1. $\mathrm{CF} / \mathrm{PC}$ (sheet: UD) has the highest bending strength and bending modulus among three kinds of specimens. This is due to the good impregnation property of CF/PC (sheet: UD).

2. Maximum load of drop weight impact test of $\mathrm{CF} / \mathrm{PC}$ (plain weave: UD) is higher than $\mathrm{CF} / \mathrm{PC}$ (sheet: UD). $\mathrm{CF} / \mathrm{PC}$ (sheet: UD) is higher in maximum load and absorbed energy than $\mathrm{CF} / \mathrm{PC}(\mathrm{NCF})$.

\section{Acknowledgements}

This study was partially supported by the high technological research project at the "Research and Development Center for Advanced Composite Materials" of Doshisha University and the Ministry of Education, Culture, Sports, Science and Technology, Japan.

\section{References}

[1] Uotani, S., Yanagisawa, M., Itou, J. Japan Society for Composite Materials, 25(6), 236-239 (1999).

[2] Nomaguti, K., J. Japan Society for Composite Materials, 32(3), 100-112 (2006).

[3] Paesano, A., Cohee, D., Palmese, G. R., J. Compos. Mater., 16(2), 139-170 (2003).

[4] Taki, T., Amaoka, K., J. Japan Society for Composite Materials, 24(2), 4148 (1998).

[5] Ishikawa, R., J. JSPP, 17(5), 294-299 (2005).

[6] Kimoto, Y., J. Japan Society for Composite Materials, 32(4), 147-150 (2006).

[7] Huntley, M. P., et al., Proc. Inst. Mech. Eng. Pt. L. J. Mater. Des. Appl, 220(4), 229-236(2006).

[8] Matsui, J., Reinforced Plastics, 44(11), 458-465 (1998).

[9] Silverman, E.M., Forbes, W.C., "Cost analysis of thermoplastic composites processing methods for spacecraft structures" SAMPE Journal, Vol.26, No.6 pp. 9-15 (1990).

[10] Rezaei, F., Yunus, R., Ibrahim, n A., Mahdi, E. S., Development of ShortCarbon-Fiber-Reinforced Polypropylene Composite for Car Bonnet Polymer Plastics Technology and Engineering Vol.47No.4/6Page.351-357 (2008).

[11] Eco-efficient Manufacturing Process of Fiber Reinforced Thermoplastic, Kazuto Tanaka, Tsutao Katayama, Kazutaka Uno, WIT Transactions on the Built Environment, 97, pp. 203-210. 